\title{
O Topocídio da Ponte Hercílio Luz
}

\section{The Topocidio of Hercílio Luz Bridge}

\author{
Milton Luz da Conceição ${ }^{1}$ \\ miltonluzdaconceicao@gmail.com
}

\section{Resumo}

A pretensão deste artigo é apresentar a ascensão e o posterior esquecimento da Ponte Hercílio Luz como símbolo da modernização da cidade de Florianópolis (SC) dentro de seu lento processo de evolução urbana. A preponderância deste objeto arquitetônico sobre a paisagem urbana por 40 anos criou no imaginário desta população uma referencia para toda a região. $\mathrm{O}$ declínio e morte deste símbolo urbano decorre de uma abrupta expansão urbana, reflexo do fenômeno da globalização e produto das alterações da divisão internacional do trabalho nos anos 80 do século XX. A repercussão destes eventos sobre a cidade em questão afetou profundamente a gestão e a produção do espaço urbano. A recepção desenfreada a uma imigração em busca de melhores condições de vida, atraída pelo marketing turístico, abalou as estruturas econômicas e sociais. O aumento em 400\% da população em somente uma década teve como resultado a descaracterização dos valores locais, com o abandono de suas crenças e seus símbolos. A nova cidade que surge daí guarda tênues lembranças de seu passado, portanto, a ação da nova sociedade sobre os espaços e os objetos sofrerá transformações.

Palavras-chave: Topofilia; Evolução urbana; Aculturação; Turismo; Globalização.

\begin{abstract}
The intention of this article is to present the rise and the subsequent neglect of the Hercilio Luz Bridge as a symbol of modernization of Florianopolis (SC) in its slow process of urban evolution. The preponderance of this architectural object of the cityscape for 40 years created in the imaginary of this population a reference to an entire region. The decline and death of this city symbol reflects the abrupt urban expansion that is part of the globalization phenomenon and a product of changes in the international division of labor in the 1980's. The impact of these events on the city in question deeply affected the management and the production of urban space. Rampant reception to an immigration in search of better living conditions, attracted by tourism marketing, shook the economic and social structures. The increase in $400 \%$ of the population as only a decade has resulted in the disfigurement of local values by abandoning their beliefs and symbols. The new town arises then guard faint memories of his past, so the action of the new society on the spaces and objects undergo transformations.
\end{abstract}

Keywords: Topophilia; Urban evolution; Acculturation; Tourism; Globalization.

1 Doutor em Geografia Humana pela Universidad Complutense de Madri, com Master em Desenvolvimento de Cidades pela Universidad Politecnica de Madri. Arquiteto e urbanista pela Universidade Federal de Santa Catarina (UFSC). Atualmente, é professor adjunto III do Departamento de Arquitetura e Urbanismo da UFSC. 


\title{
Introdução
}

A pretensão que se tem com este artigo é apresentar a lenta evolução urbana da cidade de Florianópolis, capital do Estado de Santa Catarina, seu ingresso na modernidade, marcado pela construção da ponte Hercílio Luz, e seu crescimento acelerado a partir dos anos 80 do século XX. Destaca-se nesta última fase o processo de aculturação que sofre a população local, com a perda de parte de suas referências e abandono de seus antigos símbolos, acompanhados da profunda transformação da paisagem urbana.

A já citada ponte é um destes símbolos materiais, cuja preponderância sobre a paisagem urbana por 40 anos criou uma referência no imaginário da população de toda uma região. O declínio e morte deste símbolo urbano decorre de uma abrupta expansão urbana, que é reflexo do fenômeno da globalização é produto das alterações da divisão internacional do trabalho nos anos 1980. A repercussão destes eventos sobre a cidade em questão afetou profundamente a gestão e a produção do espaço urbano. A recepção desenfreada a uma imigração em busca de melhores condições de vida, atraída pelo marketing turístico, abalou as estruturas econômicas e sociais. O aumento em 400\% (IBGE, 2013) da população em tão somente uma década teve como resultado a descaracterização dos valores locais, com o abandono de suas crenças e seus símbolos. A nova sociedade que surge daí guarda tênues lembranças de seu passado; portanto, a ação sobre os espaços e os objetos dará novas feições à cidade.

\begin{abstract}
Quando a sociedade age sobre o espaço, ela não o faz sobre os objetos como realidade física, mas como realidade social, formas-conteúdo, isto é, objetos sociais já valorizados, aos quais ela (a sociedade) busca oferecer ou impor um novo valor. A ação se dá sobre objetos já agidos, isto é, portadores de ações concluídas, mas ainda presentes. Esses objetos da ação são desse modo, dotados de uma presença humana e por ela qualificados. (SANTOS, 2006, p. 71).
\end{abstract}

\section{Florianópolis, o ingresso na modernidade}

Analisando o processo de formação da cidade de Florianópolis, antiga Vila de Nossa Senhora do Desterro, podemos dizer que sua origem, ou elemento gerador, é seu porto marítimo. A estruturação urbana junto ao porto se complementa com a consolidação da malha ao seu redor. Na segunda metade do século XIX, a vila tinha, além de seu movimentado porto e mercado, um centro histórico limitado. A praça mais 47 ruas adjacentes, com oito becos a elas conectados, conformavam os espaços de circulação, de comunicação e de trocas, caracterizando um meio não edificado. Esta malha se implanta a partir de 1673 de forma paralela ao mar, a oeste da praça, entre o mercado e o porto. As primeiras construções eram improvisadas, sua morfologia primitiva é de má qualidade construtiva, sendo que a estruturação urbana respeitava as condições da Provisão Real de $1747^{2}$. Aos poucos, técnicas construtivas mais avançadas, com formas que buscavam certa sofisticação, vão ganhando espaço por influência das grandes metrópoles de então. O crescimento do comércio provocará uma grande metamorfose na paisagem urbana da metade do século XIX até metade do século XX (Ilustração 1), como consequência direta da influência sobre o enclave do que Ribeiro (1999, p. 431) chama de imigração tardia, ou seja, o grande número de imigrantes europeus não ibéricos, chegados durante todo o século XIX.

A ampliação das atividades mercantis faz com que ao fim deste século pelo menos três ruas do centro histórico já tenham uso misto, comercial e residencial. A tipologia é a de rua de fachada contínua formando um corredor, consequência não só dos costumes da época, mas também da rigorosidade das administrações locais. O limite entre o público e o privado coincide com o plano da fachada, sem nenhum espaço de transição.

A Revolução Federalista, em 1894, estabeleceu a sede de sua república independente no Desterro durante meio ano. Os revolucionários federalistas dos três estados do sul, unidos aos também rebelados militares da Marinha do Brasil, foram fragorosamente derrotados. Após o fracasso da revolta, o nome da cidade é trocado como forma de castigo/homenagem ao vencedor, encerrando um dos mais sangrentos episódios da história brasileira.

2"No sítio destinado ao lugar assinalará um quadro para a praça, de quinhentos palmos de face, e num dos cantos se porá a igreja, a rua ou ruas se demarcarão ao cordel com largura ao menos de 40 palmos; por elas e nos lados da praça se porão as moradas em boa ordem, deixando entre umas e outras, e para trás, lugar suficiente e repartido para quintais”. Trecho da Provisão Real de D. João V, de 1747 em SILVEIRA (1999, p. 28). 
A insurgência contra o governo central republicano de Floriano Peixoto encerra um ciclo e marcará para sempre a cidade, não só por sua mudança de nome de Nossa Senhora do Desterro, ou simplesmente Desterro, para Florianópolis, mas também pela consolidação da índole conservadora de sua gente e sua tendência ao isolamento a partir de então.

O século XX inicia com uma promessa de transformação por parte dos novos governantes, que têm na figura de Hercílio Luz sua principal liderança. A modernidade sustenta este desejo de mudança e a promessa da construção de uma ligação da Ilha de Santa Catarina ao continente é como um visto de entrada de Florianópolis neste novo período. Como nos lembra Habermas (2002, p. 12), "a modernidade não pode e não quer tomar dos modelos de outra época os seus critérios de orientação, ela tem que extrair de si mesma a sua normatividade”.
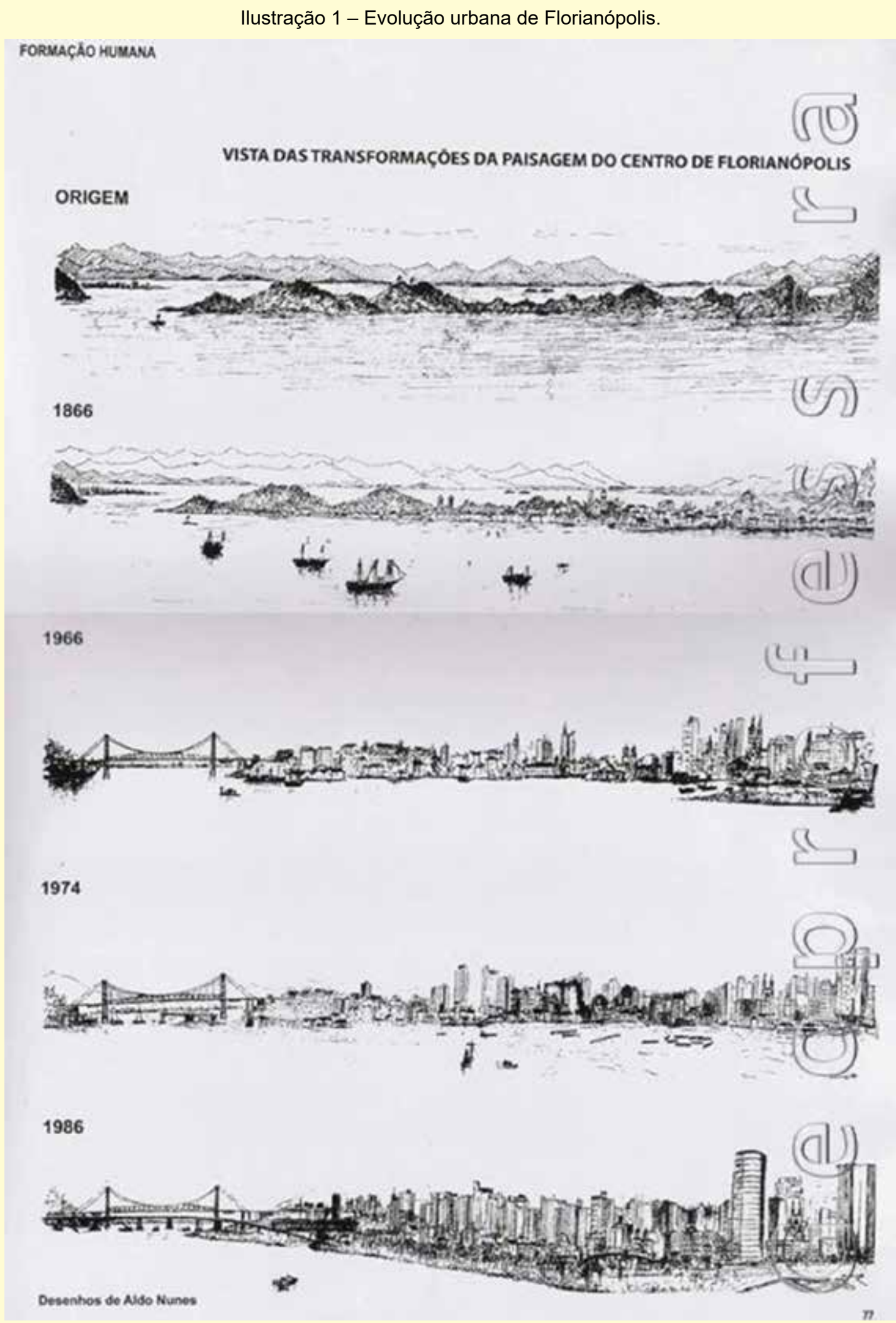

Fonte: Floripendio (2012). 
Hercílio Luz (1860 - 1924) executou esta obra no segundo de seus três mandatos como governador, entre 1918 e 1922. Foi um governante preocupado com a integração de todas as regiões da Província, depois Estado de Santa Catarina. É esta preocupação quase obsessiva que o leva à construção da ponte, chegando, em determinado momento, a propor a mudança da capital caso não obtivesse os recursos necessários.

Em busca destes recursos, executam-se uma série de obras visando reformar e consolidar Florianópolis como cidade voltada para o mundo e equiparada às cidades modernas, ainda que fosse uma modernidade periférica, como acredita Beatriz Sarlo (2010, p. 12) e Silveira da Costa (2007, p. 27), para quem "Florianópolis não acompanhou a velocidade das reformas urbanas de cidades como o Rio de Janeiro, capital política e centro econômico do país, na época. Constituía-se, desta forma, uma modernidade distante e periférica".

A reforma urbana de Hercílio avança em várias frentes: a abertura da Avenida do Saneamento, hoje Avenida Hercílio Luz, financiada pela internacional Fundação Rockfeller; a canalização do Rio da Bulha, um córrego lento, quase plano, encarregado de transportar todos os dejetos da parte mais pobre da cidade para o mar; o encaminhamento da construção da ponte Ilha/Continente; a aquisição da Fazenda Ressacada, permitindo a construção do Aeroporto Hercílio Luz; a reformulação da iluminação elétrica da cidade; as obras de reforma na Catedral e no Palácio do Governo; o alargamento de ruas através do novo sistema viário urbano, idealizado por Adolfo Konder em 1920, que propunha um anel envolvendo a cidade, ladeando o mar e o morro do Antão com ruas largas e avenidas. Porém, a mais arrojada obra, uma ferrovia cruzando Santa Catarina de leste a oeste a partir do porto de Florianópolis, não foi realizada.

Estas obras vão somar-se à reforma sanitária, iniciada em 1884 pelo governador Gustavo Richard, antecessor de Hercílio Luz, com a coleta de lixo continuada, a construção da primeira rede de abastecimento de água, inaugurada em 1910, e a implantação da rede de esgotos e construção do forno incinerador de lixo, ambas em 1916.

Os 14 mil florianopolitanos de então passam a desfrutar dessas melhorias, que têm como ápice a inauguração da ponte, cujo contrato de construção é assinado em 27 de setembro de 1920.

\section{A Ponte Hercílio Luz}

A ponte pênsil conectando a Ilha de Santa Catarina ao continente é, sem sombra de dúvida, a maior obra pública realizada no Estado de Santa Catarina durante a primeira metade do século XX. Além de impressionar por seu arrojo e beleza, a mesma colocou a cidade entre as poucas do mundo a contar com um equipamento de última tecnologia à época.

Os trâmites para tal realização iniciam com a tomada de empréstimo internacional junto ao grupo financeiro norte-americano Imbrie \& Co, no valor de 5 milhões de dólares. A falência deste agente poucos anos de-

Imagem 1- Ponte Hercílio Luz em construção (1924).

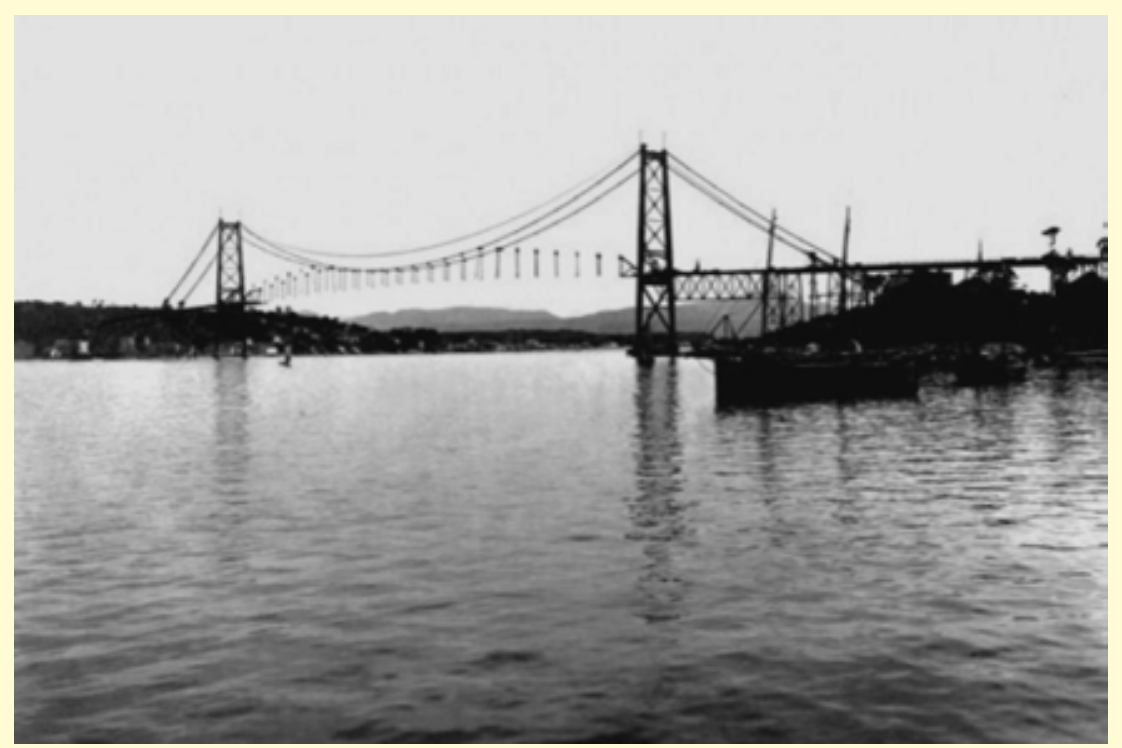

Fonte: Bündgens (2014, p. 19). pois, além de atrasar o início das obras, forçou uma renovação do crédito junto a Halsey Stuart \& Co, com 5 mil títulos de mil dólares cada, colocados no mercado pela Trust Equitable Company of New York contra o Estado de Santa Catarina, com prazo de 30 anos.

A construtora Bymington \& Sundstrom, dos Estados Unidos, inicia as obras da Ponte Hercílio Luz em 21 de novembro de 1922 (Imagem 1), com a responsabilidade de executar os projetos dos engenheiros norte-americanos David B. Steinmar e Holton D. Robinson. A fiscalização brasileira ficou a cargo de uma comissão integrada pelo engenheiro Paulo de Frontin, entre outros. 
Em 13 de maio de 1926, a obra estava pronta, com um ano de atraso. Hercilio Luz, falecido em 1924, foi substituído por Pereira de Oliveira até março de 1926, quando assume Bulcão Viana, finalmente o governante que inauguraria a ponte (Imagem 2), a qual nasceu com características de ícone urbano dominante na paisagem.

\section{O surgir do ícone}

A construção conhecida pelos florianopolitanos como a ponte, e sua carga de significação, fazem parte do imaginário local desde o primeiro dia. A escala monumental de suas formas impacta o visitante, mesmo atualmente. A sua localização estratégica domina toda a paisagem, como podemos perceber na Imagem 3. A expectativa de sua implantação e uso, proposto como locomotora do progresso que se avizinhava, despertou um sentimento de tal magnitude que, desde sua concepção, a consolida como ícone urbano.

Imagem 2 - Ponte Hercílio Luz (Anos 40).

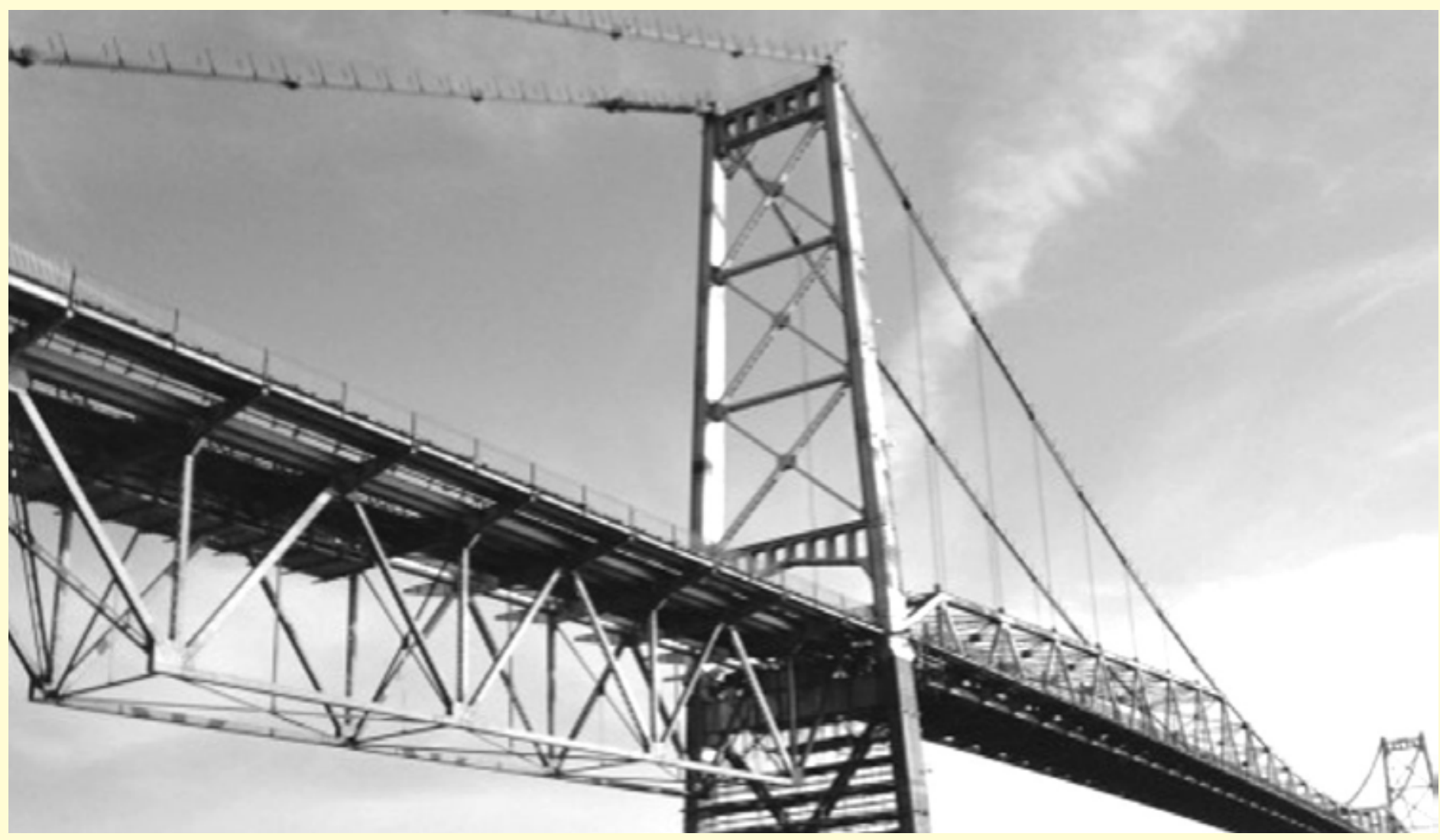

Fonte: Hayashi e Barth (2015).

Mesmo nascida com objetivos políticos e de desenvolvimento estratégico, incorporou-se como símbolo da sociedade local atribuindo vitalidade ao espaço urbano. Destacada por sua verticalidade, isolada de outros elementos, a evolução da cidade com a construção de outros edifícios só consolidou sua posição, sendo que, ao longo dos anos, nenhuma outra construção foi capaz de capturar a atenção da população. Este objeto, até o final do século XX, foi reconhecido como o verdadeiro ícone da cidade.

Entenda-se por ícone construção de impacto, seja por sua localização estratégica, visibilidade, escala, forma, aparência, monumentalidade ou uso. Ícone é aquela construção que, desde a sua concepção, vem causar alguma expectativa em relação à sua implantação (HAZAN, 2008).

Embora seja um ícone surgido na modernidade, lembra os edifícios da antiguidade clássica sob o aspecto de catalisador auxiliar no processo de desenvolvimento da cidade. O olhar dos habitantes sobre seu ambiente traduz suas experiências e é a partir de um referencial concreto que a totalidade simbólica da 
ponte Hercílio Luz construiu sua identidade. Com esta mesma identidade adquire status de ícone urbano. Sua rápida incorporação à paisagem fez com que, mesmo sendo construída sem esta intenção, a cidade se desenvolvesse à sua volta mantendo-se em destaque e assumindo a posição de mito representativo da cidade, pelo menos até os anos sessenta do século XX. A partir deste período, as transformações urbanas e sociais vão ganhar velocidade, em descompasso com o até então lento e pouco relevante desenvolvimento ilhéu.

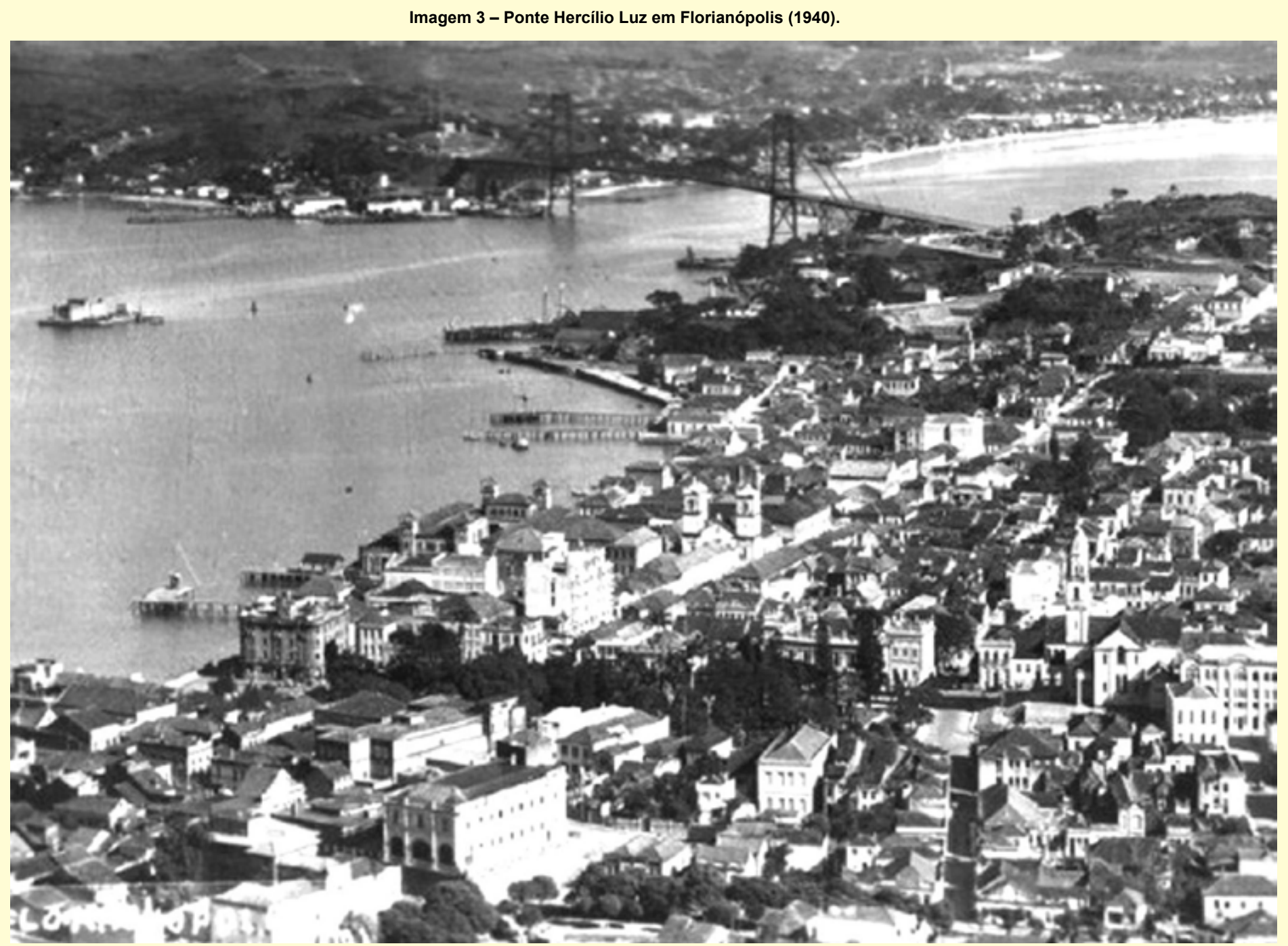

Fonte: Hayashi e Barth (2015).

\section{O topocídio}

Como parte destas transformações urbanas e sociais, teremos primeiramente a exportação crescente da população excedente para o sul do centro urbano e para o continente, criando espaços periféricos e degradados. A chegada do turismo nos anos setenta aponta o norte da ilha como local para os investimentos desta nova atividade. Estes investimentos, guiados pela lógica da localização, se concentram na costa marítima norte. A presença do turismo como ordenador do território é denunciada pela explosão do setor terciário local. A chegada dos grandes supermercados, shopping centers, hotéis, e o desenvolvimento dos transportes geraram uma hipertrofia na paisagem urbana do norte da ilha.

A ilha de Santa Catarina possui inegáveis aspirações turísticas, imagens mentais que geram mitos espaciais, praias de areias brancas, dunas e mar azul. A relação entre estes mitos e o produto turístico é resultado da estrutura econômica dos investimentos, marketing e outros mecanismos que fazem a interação entre um e outro, estimulando a demanda social. Assim, se constrói espacialmente o produto turístico, que reflete as opções da economia sobre o espaço, projetando aí os ideais da sociedade global. O choque que estas transformações projetam sobre a população autóctone a divide em dois grupos. O primeiro, formado pelos que 
se adaptam com rapidez às mudanças, beneficiando-se delas pela supervalorização dos aluguéis e imóveis, fruto da repentina corrida imobiliária. Este primeiro grupo é logo absorvido pelos novos postos de trabalho gerados pelas novas atividades de serviço. Um segundo grupo, composto pela população que resiste por um tempo em sua propriedade, para ser expulsa em seguida pela valorização do solo, perdendo, além de suas terras, sua referência cultural.

A relação entre o turismo e a antiga estrutura espacial do território provoca um conflito cultural também em relação à composição dos espaços que abandonam seu valor de uso para ganhar um valor de troca até então desconhecido. Este novo valor, eminentemente mercantil, contribui para a destruição das atividades de subsistência, como a pesca artesanal e a agricultura, provocando uma fragmentação no território, que aloca uma importante quantidade de atividades de prestigio comercial sobre os até então espaços de produção. Fragmentação esta que é excludente, já que grande parte da população não se adapta à nova divisão do trabalho, não conseguindo ocupar a oferta de empregos, o que gera novas pobrezas e fazem surgir espaços periféricos e degradados junto à nova conformação territorial. Estes novos espaços periféricos, localizados nas bordas dos grandes investimentos, serão engrossados pela grande migração em direção à ilha, em busca dos empregos e da qualidade de vida prometidos pelo marketing anunciador da atividade turística.

A consequência destes fatores é percebida nas pesquisas do IBGE que constataram, entre 1970 e 1991, um crescimento populacional no norte da ilha três vezes maior que no restante do território em questão. A migração provoca também um aumento significativo das atividades comerciais nos bairros periféricos, gerando novas centralidades.

Depois dos anos setenta, o poder de atração que a cidade e toda a Ilha de Santa Catarina passam a exercer sobre os outros estados foi capaz de provocar uma migração interna que, segundo dados do IBGE (2013), aumentou sua população de 115.547 habitantes, em 1970, para 421.203 no ano de 2010, enquanto a região metropolitana de Florianópolis passou de 192.000 habitantes para 1.012.831 habitantes no mesmo período. Este aumento populacional de quase 400\% em Florianópolis e 500\% junto aos municípios conurbados continentais tem raízes na convergência de vários fatores, alguns refletindo as conjunturas econômicas nacionais do período, outros específicos conectados a questões regionais.

Como já dito, a atividade comercial que inicialmente se concentrava no centro histórico vai migrar, em função deste acréscimo populacional, para regiões imediatamente periféricas, formando aí centralidades secundarias em novos bairros, e reforçando a importância do núcleo fundante de Florianópolis. Os outros núcleos do interior ganham nova visibilidade, suas centralidades se revigoram, provocando novas periferias no interior da ilha.

O centro histórico, ou seja, o tradicional coração da cidade vai, a partir dos anos 1990, sofrer um processo de declínio comercial acentuado e consequente degradação física. Florianópolis não foge à velha estratégia da especulação imobiliária, que leva à degradação os centros históricos para comprá-los, posteriormente, por valores depreciados, e imediatamente forçar processos de revitalização urbana por parte da administração pública, revalorizando a área e apropriando-se das rendas diferenciais.

Assim, a recomposição do centro histórico começa no início do século XXI, a partir das áreas centrais recém-adquiridas pelo capital especulativo, acrescidas dos vazios urbanos já existentes, alterando a morfologia do espaço e criando uma nova tipologia arquitetônica.

A população residente foi expulsa e, salvo alguns poucos edifícios residenciais dos anos 1970, o comercio popular ocupou todo o entorno do antigo Mercado Público. O comercio mais ao norte da Praça XV foi substituído por um centro de prestação de serviços, onde grandes corporações e profissionais liberais ocupam escritórios, em novos edifícios, com as ruas adquirindo um aspecto homogeneizado de arquitetura contemporânea, espetacularmente incrementada, nos últimos anos, pela demanda imobiliária para esta tipologia arquitetônica.

As vias de acesso rápido que conduzem aos antigos núcleos do interior da ilha, e agora novos bairros periféricos, são ladeadas por pacotes imobiliários que ora têm um grande centro comercial como elemento de atração, e ora têm Garden Centeres e outros centros de consumo, criando vários nichos, de maior ou menor prestigio, dentro deste quadro de fragmentação urbana que vai se reproduzindo por toda a ilha. Nos antigos 
núcleos do interior da ilha, agora revalorizados e super-habitados, temos novamente a tipologia arquitetônica denunciando a atividade, a função e as pautas de consumo que aí acontecem. Nos núcleos próximos ao litoral, de exuberante natureza, predominam os hotéis de luxo, os grandes resorts e as pequenas lojas de objetos de luxo, entre restaurantes e casas noturnas, formando shoppings a céu aberto, numa tipologia já bastante tradicional para este tipo de espaço e seus frequentadores. Aí também se estabelece a habitação de temporada das elites econômicas. Nos espaços mais afastados da costa, as comunidades, testemunhas da ocupação colonial polinucleada da Ilha de Santa Catarina, formam bairros de grandes conjuntos habitacionais, onde residem os trabalhadores responsáveis pela inclusão deste pedaço do planeta nos catálogos do turismo internacional. Nestes, a tipologia arquitetônica se assemelha aos demais bairros periféricos, não só os do sul da cidade de Florianópolis, mas também de todo o país, tendo sempre como protagonista os antigos armazéns ou vendas, que agora se transformaram em mercadinhos de bairro, reforçando a influência de centenárias famílias locais, proprietárias destes negócios e adaptadas aos novos tempos.

Dentro deste quadro de profundas e radicais transformações no espaço urbano e social da Ilha de Santa Catarina, era de se esperar também a mudança de seus valores culturais. As populações recém-chegadas e responsáveis pelo maior crescimento de uma cidade/capital brasileira em três décadas trazem também consigo novos valores, usos e costumes. A frágil cultura europeia da ilha, advinda do arquipélago português dos Açores, será aculturada uma segunda vez - a primeira vez teria sido em contato com os nativos locais, como nos lembra Ribeiro (1999, p. 427):

\footnotetext{
Outra configuração histórico-cultural constitui-se no Brasil sulino formada por populações transladadas dos Açores no século XVIII pelo governo português. O objetivo dessa colonização era implantar um núcleo de ocupação lusitana permanente para justificar a apropriação da área em face do governo espanhol e também para operar como uma retaguarda fiel das lutas que se travavam nas fronteiras. Esses açorianos vieram com suas famílias para reconstituir no Sul do Brasil o modo de vida das ilhas, atraídos por regalias especialíssimas para a época. Prometiam-lhes a concessão de glebas de terra demarcadas como propriedade de cada casal [...]. Fizeram-se matutos, ajustando-se a um modo de vida mais indígena que açoriano, lavrando a terra pelo sistema de coivara, plantando e comendo mandioca, milho, feijões e abóboras. Mesmo no artesanato praticado hoje nos núcleos de seus descendentes, não se pode distinguir peculiaridades açorianas. É essencialmente o mesmo das populações caipiras e assim deve ter sido no passado, para suprir suas necessidades de panos, de tralha doméstica feita de trançados e de cerâmica e de instrumentos de trabalho [...]. Sua contribuição à cultura neo-brasileira foi nula porque esta se havia saturado dos traços do patrimônio português que podia absorver. Sua influência na cultura regional e seu papel social foram, todavia, decisivos no aportuguesamento linguístico e no abrasileiramento cultural da campanha e, sobretudo, na constituição do núcleo leal ao poderio português e, mais tarde, imperial, que se requeria naquelas fronteiras, por um lado tão remarcadamente castelhanas e, pelo outro, tão independentes em sua lealdade a caudilhos autônomos.
}

$\mathrm{Na}$ gradual eliminação do significado cultural dos valores e crenças locais, com seu consequente translado ao espaço físico, percebemos o surgir de uma nova percepção da paisagem urbana na ilha: "uma paisagem representa diferentes momentos do desenvolvimento da sociedade" (SANTOS, 2006, p. 77).

A mudança e a substituição de valores culturais, trazidas pela grande massa de recém-chegados, e sua relação com os símbolos representativos da população nativa se fazem sentir abruptamente. As danças folclóricas, a cultura da pesca artesanal, e o linguajar logo se tornam motivo de chacota para os novos habitantes que, segundo o projeto Observatório das Migrações em Santa Catarina, vinculado ao Centro de Ciências Humanas e da Educação (FAED) da Universidade do Estado de Santa Catarina (Udesc), na atualidade 52,18\% dos habitantes de Florianópolis não nasceram no município ${ }^{3}$, como mostra a Tabela I.

\footnotetext{
3 Dos 421.240 habitantes de Florianópolis, 219.819 deles não nasceram no município, ou seja, 52,18\% da população residente não é natural da cidade. Ademais, 127.978 habitantes de Florianópolis não nasceram sequer em Santa Catarina, o que corresponde a 30,38\% da população residente do município.
} 


\section{TABELA I - POPULAÇÃO RESIDENTE E MIGRANTES NOS ÚLTIMOS 5 ANOS (REGIÕES SELECIONADAS EM 2010).}

\begin{tabular}{|c|c|c|c|}
\hline Região ou Município & População Residente & Imigrantes nos últimos 5 anos & $\begin{array}{c}\text { \% da população residente que } \\
\text { chegou nos últimos 5 anos }\end{array}$ \\
\hline Santa Catarina & 6.248 .436 & 736.702 & 11,7 \\
\hline Grande Florianópolis & 994.095 & 144.307 & 14,5 \\
\hline Florianópolis & 421.240 & 63.215 & 15 \\
\hline São José & 209.804 & 31.461 & 14,9 \\
\hline Palhoça & 137.334 & 20.944 & 15,25 \\
\hline
\end{tabular}

Fonte: Udesc (2013, p. 9).

A tendência da população nativa, que a principio foi de recolher-se aos seus valores, demonstrando uma resistência que beirava a xenofobia, passou a entregar-se com o tempo aos novos ditames.

O papel de principal ícone urbano e turístico da ponte Hercílio Luz no imaginário local aos poucos vai sendo substituído por novas imagens, com apelo mais internacional, produzidas de acordo com os interesses do marketing turístico.

A percepção externa de um signo, como uma estátua no meio de uma praça, por exemplo, tem características físicas, captadas por quem as observa que não deixam dúvidas. O significado desta estátua, porém, pode variar muito de um observador para o outro. Este fato se dá pela leitura que cada um faz, levando-se em conta o conhecimento sobre o que a estátua representa as características culturais do observador, sua disposição interna no momento da observação, além de uma série de outros fatores que podem interferir no resultado final do significado para cada um [...]. Mas, para os que não são do grupo, ou não tem conhecimento sobre o que representam [...] simplesmente nada significam (ROCHA, 2006, p. 39).

Estas mudanças sofridas pela dinâmica social e econômica da Ilha de Santa Catarina terão, evidentemente, reflexos na sua morfologia espacial. No que tange o espaço específico ocupado pelo objeto em questão, as alterações foram radicais. A Ponte Hercílio Luz vai perder protagonismo espacial com as infraestruturas para conduzir os efeitos da expansão ao interior da ilha. A avenida, lançada sob o objeto em estudo, e os novos edifícios construídos em suas laterais, acabam com o isolamento que o destacava. A construção de uma nova ponte (a Colombo Salles, inaugurada em 1975) vai provocar o fechamento da Hercílio Luz ao tráfego de veículos em 1982. Em 1990, mais uma ponte (a Pedro Ivo) relega definitivamente a ponte Hercílio Luz ao ostracismo.

Novos governantes, oriundos das populações recém-chegadas, conduzem este ícone urbano ao esquecimento, apoiados pela repaginada sociedade local, com alguns grupos até incentivando a sua desmontagem.

Os ícones urbanos, na medida em que perdem sua importância no imaginário da população, se aproximam do que Tuam (1980) classifica como topocídio - tomando o termo emprestado de Douglas Porteous (1988) - para explicar a eliminação do significado cultural atribuído por uma determinada sociedade a uma dada paisagem, o que é um caminho sem volta para a aniquilação de uma cultura, pois expõe sua fragilidade, mediante as forças topocídicas. Como escreve o autor:

\footnotetext{
A ilusão de superioridade e centralidade provavelmente é necessária para a manutenção da cultura. Quando a crua realidade despedaça essa ilusão, é possível que a própria cultura decline. No mundo moderno de comunicações rápidas é difícil para as pequenas comunidades acreditarem que estejam, em qualquer sentido literal, no centro das coisas, embora algo dessa fé seja necessário se elas desejam prosperar (TUAN, 1980, p. 36).
}

A partir de sua interdição, em 22 de janeiro de 1982, a Ponte Hercílio Luz passou a ser considerada, para a administração local, mais como um estorvo urbano do que símbolo de um passado presente.

Passados 10 anos, com o surgir de incentivos à cultura por parte do governo federal, começaram a encarar o objeto como forma de alavancar recursos, usando seu restauro como pretexto. Dentro desta ótica, 
em 04 de agosto de 1992 é feito o seu tombamento como Patrimônio Histórico, Artístico e Arquitetônico do Município de Florianópolis.

llustração 2 - Dados sobre a Ponte Hercílio Luz.

\section{Números da Ponte}

A ponte Hercilio Luz é uma das maiores pontes pènseis do mundo e a maior do Brasil.

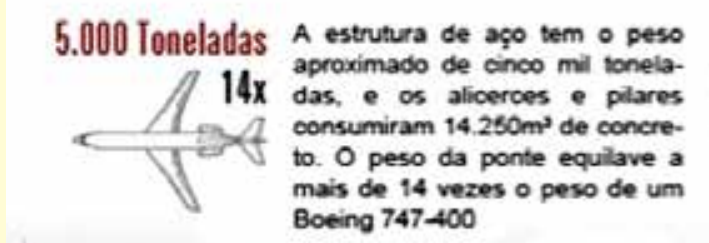

\section{Cadeias de barras de ollhal}

A carga total nas cadeias de barras de olhal é de 4.000 toneladas-força. Boeing 747400

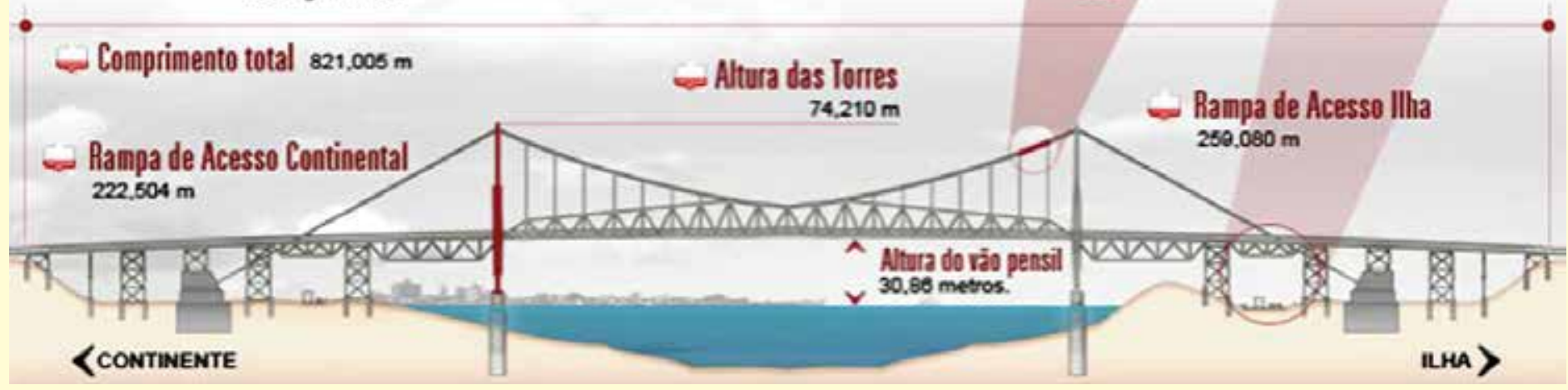

Fonte: Santa Catarina/ Deinfra (2015).

Após a captação de muitos recursos pelos governos estadual e municipal, vários projetos foram elaborados, porém nenhum encarado com a responsabilidade exigida. Finalmente em março de 2005, 23 anos após o seu fechamento, o governo de Santa Catarina apresenta um projeto de reabilitação da Ponte Hercílio Luz.

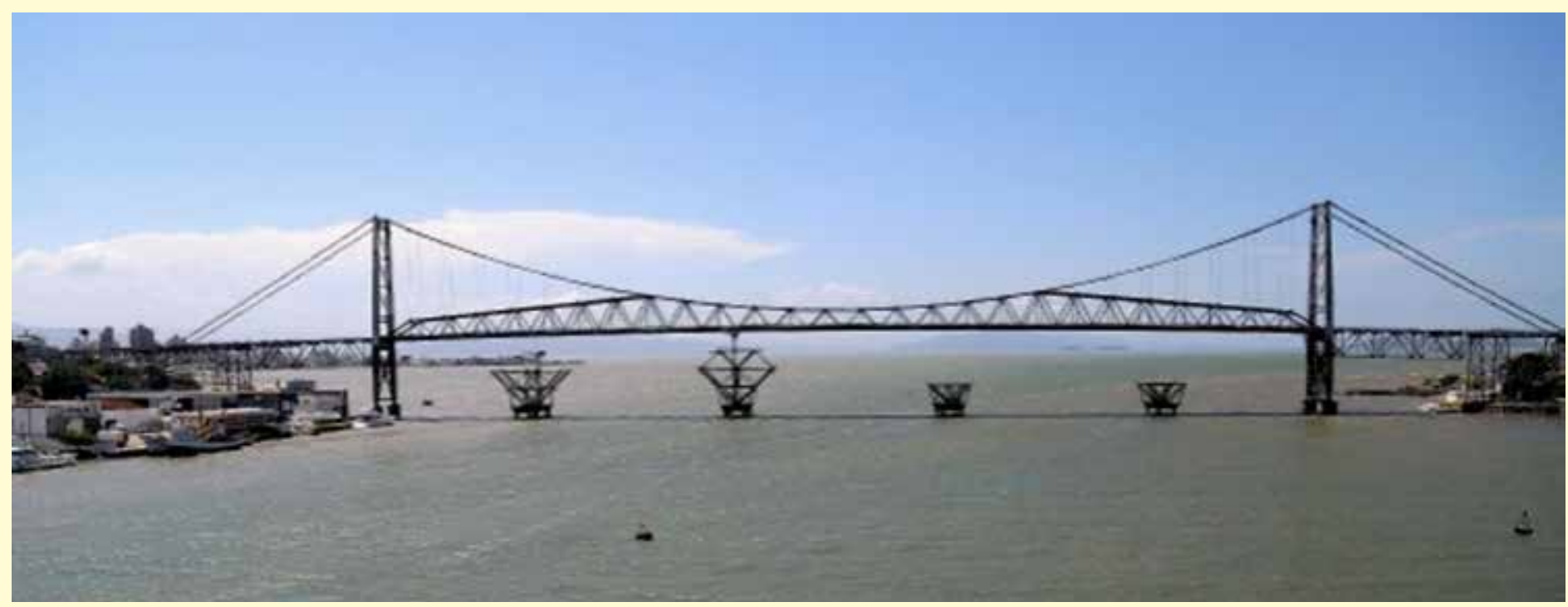

Fonte: Santa Catarina/Secom (2015).

O projeto descaracteriza o objeto (Imagem 4), pois abandona os dois pilares fundamentais de qualquer teoria de restauração, ou seja, história e arte. Apresenta uma proposta que aponta unicamente para uma a atitude simplista, reduzindo o trabalho de reabilitação a uma mera adaptação da matéria à obra em sua exigencia formal, desconhecendo os envolventes históricos da memória e da cultura. Mesmo assim, a execução de tal projeto se arrasta a mais de dez anos não tendo data prevista para sua conclusão, denunciando o descompromisso de governantes e população com o símbolo de uma sociedade e de uma cidade que talvez já não existam nos novos tempos. 


\title{
Considerações finais
}

Finalmente, mesmo diante da dificuldade de explicitar em um artigo a abrangência de uma investigação em curso, apresentamos a ideia de se buscar, sobre o território da cidade de Florianópolis e em sua ampliação, a Ilha de Santa Catarina, marcas de momentos e objetos históricos determinantes para sua evolução urbana, visando uma saída para a compreensão de um passado recente, atropelado por metamorfoses sofridas em consequência de migrações internas. As alterações no modo de produção global levaram a cidade à uma abrupta aceleração de sua evolução urbana, como vemos na Imagem 5.

\begin{abstract}
Na família dos imaginários da globalização e das técnicas, encontra-se a ideia, difundida com exuberância, de que a velocidade constitui um dado irreversível na produção da história, sobretudo ao alcançar os paroxismos dos tempos atuais. Na verdade, porém, somente algumas pessoas, firmas e instituições são altamente velozes, e são ainda em menor número as que utilizam [...]. Pode-se dizer que a velocidade assim utilizada é duplamente um dado da política e não da técnica. De um lado, trata-se de uma escolha relacionada com o poder dos agentes e, de outro, da legitimação dessa escolha, por meio da justificação de um modelo de civilização. É nesse sentido que estamos afirmando tratar-se mais de um dado da política que, propriamente, da técnica, já que esta poderia ser usada diferentemente em função do conjunto de escolhas sociais. De fato, o uso extremo da velocidade acaba por ser o imperativo das empresas hegemônicas e não das demais, para as quais o sentido de urgência não é uma constante (SANTOS, 2001, p. 122).
\end{abstract}

O objeto estudado faz parte, num primeiro momento, da arquitetura das transformações urbanas que introduzem a cidade na modernidade e, num segundo momento, representa a morte dos valores locais frente ao processo de globalização.

Este segundo momento se inicia nos anos 80 do século $\mathrm{XX}$, quando o projeto da economia neoliberal sai vencedor no mundo ocidental, levando suas cidades a um setor terciário avançado, sedento de novas imagens permanentemente.

Dentro desta ótica, fazemos a crítica defendendo a ideia de que os ícones urbanos não são apenas visuais, mas têm um estatuto próprio a ser considerado, o qual influencia as práticas de intervenção e, como a paisagem, está profundamente relacionado às práticas sociais.

O respeito às pré-existências é fator fundamental na relação entre os povos de migrações internas, e

Imagem 5 - Vista das três pontes (2015).

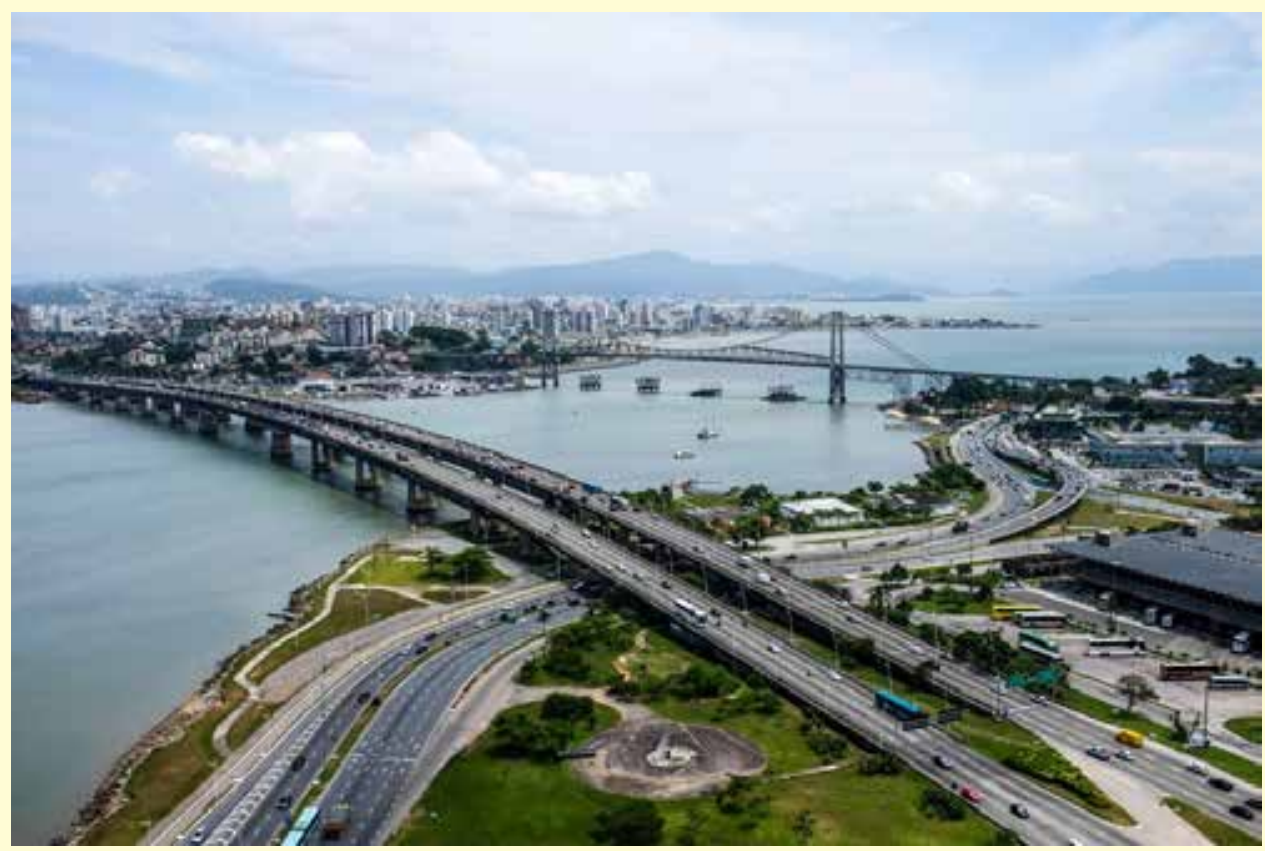

Fonte: G1 (2015). necessita ser legitimado, não como um objeto congelado no passado, mas como entendimento do respeito à manutenção do caráter e da personalidade locais.

Florianópolis é capturada por este processo com uma rapidez acima da média. As mudanças socioeconômicas, culturais e espaciais são radicais. A dinâmica da cidade acelera, e o consumo de bens e serviços é o grande locomotor destas transformações. Acreditamos que identificar estes câmbios e monitorá-los através dos reflexos em seus símbolos arquitetônicos, é possível. 
Dossiê

\section{Referências}

BOORSTIN, Daniel J. Os descobridores. 2. ed. Rio de Janeiro: Civilização Brasileira, 1989.

BRITO, Paulo José Miguel de. Memória Política sobre a Capitania de Santa Catarina. Lisboa: Academia Real das Ciências, 1829.

BÜNDGENS, F. Ponte Hercilio Lu冖: do sonho à realidade. Florianópolis: Bernuncia Editora, 2014.

CABEZA DE VACCA, A.N. Naufrágios e Comentários. Porto Alegre: L\&PM, 1999.

CABRAL, O.R. As defesas da ilha de Santa Catarina no Brasil Colônia. Florianópolis: UFSC, 1976.

FLORIPENDIO. Florianópolis ontem e hoje. Florianópolis. Disponível em: < http://www.floripendio.blogspot.com $>$. Acesso em: 24 ago. 2015.

G1. Florianópolis comemora 289 anos. São Paulo. Disponível em < http://glo.bo/1Oq7ghJ>. Acesso em: 12 nov. 2015.

HABERMAS, J. O Discurso Filosófico da Modernidade. São Paulo: Martins Fontes, 2002.

HAYASHI, Fernando Augusto Yudyro; BARTH, Fernando. Ponte Hercílio Luz em Florianópolis. Patrimônio tecnológico. Vitruvius/Arquitextos, São Paulo, ano 15, n. 178.00, fev. 2015. Disponível em: < $\underline{\text { http://www.vitruvius.com.br/ }}$ revistas/read/arquitextos/15.178/5494>. Acesso em: 12 nov. 2015.

HAZAN, Vera Magiano. O papel dos ícones da contemporaneidade na revitalização dos grandes centros urbanos. Vitrwins/Arquitextos, São Paulo, ano 4, n. 041.02, out. 2003. Disponível em < $\underline{\text { http://www.vitruvius.com.br/revistas/ }}$ read/arquitextos/04.041/645>. Acesso em: 20 ago. 2015.

IBGE. Estimativas populacionais para os municípios brasileiros em 01.07.2013. Disponível em: < http://www.ibge.gov.br/ home/estatistica/populacao/estimativa2013/estimativa dou.shtm>. Acesso em: 08 ago. 2015.

PAULI, E. A fundação de Florianópolis. Florianópolis: Edeme, 1978.

RIBEIRO, D. O Povo Brasileiro: A formação e o sentido do Brasil. São Paulo: Cia. das Letras, 1999.

RIBEIRO, O. Originalidade da Expansão Portuguesa. 3. ed. Lisboa: GP, 1994.

ROCHA, Lurdes Bertol. A região cacaueira da Babia: uma abordagem fenomenológica. 2006. Tese (Doutorado em Geografia) - Universidade Federal de Sergipe, Aracaju. 2006.

SANTA CATARINA. Assembleia Legislativa do Estado. Ilha de Santa Catarina: Relatório de Viajantes Estrangeiros nos Séculos XIII e XIX. Florianópolis: Gráfica Canarinho, 1979.

SANTA CATARINA. Departamento Estadual de Infraestrutura (Deinfra). Histórico da Ponte Hercílio Luz: Disponível em: < http://www.deinfra.sc.gov.br/jsp/informacoes sociedade/ponte HercilioLuz.jsp>. Acesso em: 14 out. 2015.

SANTA CATARINA. Secretaria de Estado de Comunicação (Secom). Governador Raimundo Colombo viaja aos Estados Unidos para negociar restauração da Ponte Hercílio Lu₹. Fotografia de Júlio Cavaleiro. Disponível em: < http://goo.gl/

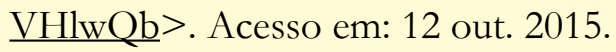

SANTOS, M. A natureza do espaço. Técnica e Tempo, Razão e Emoção. 4. ed. 2. reimpr. São Paulo: Edusp, 2006.

SANTOS, M. Por uma outra globalização: do pensamento único à consciência universal. 6. ed. Rio de Janeiro: Record, 2001.

SARLO, B. Modernidade Periférica: Buenos Aires, 1920 e 1930. São Paulo: Cosac Naify, 2010.

SILVEIRA DA COSTA, Sandro. Transfigurações urbanas em Florianópolis (1880-1930). Agora, Florianópolis, v. 1, n. 29, p. 26-33, jan./jun. 1999.

STADEN, H. Viagem ao Brasil. São Paulo: Martin Claret, 2007.

TUAN, Y.F. Espaço e Lugar: a perspectiva da experiência. São Paulo: Difel, 1983.

Topofilia: um estudo da percepção, atitudes e valores do meio ambiente. São Paulo: Difel, 1980.

UNIVERSIDADE DO ESTADO DE SANTA CATARINA (Udesc). Relatório do Observatório de Migrações em Santa Catarina. Florianópolis: IOESC, 2013. 